\title{
Morphometric Studies of Epididymis and Morphological Changes of the Spermatozoa at Different Regions of the Epididymis of the Indigenous Bulls of Sri Lanka
}

\author{
Piratheepan $\mathrm{S}^{1^{*}}$, D.M.S.Munasinghe ${ }^{2}$
}

${ }^{1}$ Department of Animal Science, University of Jaffna Sri Lanka

${ }^{2}$ Department of Basic Veterinary Sciences, Faculty of Veterinary Medicine and Animal Science, University of Peradeniya, Sri Lanka

DOI: $\underline{10.36347 / \text { sjavs.2021.v08i02.002 }}$

| Received: 13.08.2020 | Accepted: 21.08.2020 | Published: 05.02.2021

*Corresponding author: Piratheepan S

\section{Abstract}

\section{Original Research Article}

Epididymides were collected from five mature healthy indigenous bulls and transported to the laboratory on ice. Sections were taken from six different regions, two from each head, body and tail of the epididymis. The histology slides prepared were stained. The volume densities of the epididymal duct, ductular lumen, epithelium, and the intestitium were measured. The tubular and lumen diameters and epithelial and stereocilial heights were also measured. The epididymal fluid was also collected from the same six regions and stained. Sperms were counted. There was a gradual reduction in sperms with proximal cytoplasmic droplets as go along the head (72.2\%), body (16.9\%), and tail (2.2\%) region. The number of abnormal sperms was reduced from head to tail. Four types of cells; principal, apical, basal and halo cells, were observed in the epithelium. The commonest cell type found was principal cells. The halo cells were the least common cell type. The volume density of epididymal duct was high in head and tail region. The epithelial volume density decreased from head to tail region and the opposite was observed for luminal volume density. The tubular diameter found to be similar in all six regions except proximal tail which had the highest diameter $(5.9 \mathrm{~mm})$. The decrease of the epithelial height from head to tail direction contributed for the increase of the luminal diameter in the same direction. The height of stereocilia was found low in the distal head (1.2mm) and distal tail $(1.4 \mathrm{~mm})$ region compare to the rest of the regions.

Keywords: Epididymis, Morphology, Morphometric.

Copyright $(\mathcal{C}$ 2021: This is an open-access article distributed under the terms of the Creative Commons Attribution license which permits unrestricted use, distribution, and reproduction in any medium for non-commercial use (NonCommercial, or CC-BY-NC) provided the original author and source are credited.

\section{INTRODUCTION}

Male reproductive system comprises of two testes, epididymis and accessory sex organs. The sperms produced by the testes are transported through the epididymis to the ductus deferens. Epididymis is a dynamic comma shaped structure that contains epididymal duct. Epididymis can be divided macroscopically into three parts as head, body, and tail [1]. The head of the epididymis is firmly attached to the testicular capsule and receives the efferent ductules, which immediately or after some coiling join to form the wider epididymal duct. The body is less firmly attached to the testicular capsule. The tail is also firmly attached to the testis by the proper ligament of the testis [2]

The epididymis is composed of a single tortuous tube; epididymal duct, that is approximately $33-35 \mathrm{~cm}$ long in adult bull.
A sperm is a free cell composed of a flattened head, mid piece and a tail. The entire spermatozoon is covered by a plasma membrane. The spermatozoa released by the testes are immotile. During the transit of spermatozoa through the epididymis they gain maturity [1]. Sperm abnormalities can occur during spermatogenesis and passage through epididymal duct. Studies by Gutaisson [3] have shown that the sperm tail abnormalities can appear during the epididymal transition in bull. However, Rao et al. [4] reported that the sperm abnormalities appear to originate.

However, there is a dearth of information on the relationship of morphometry of the epididymis with the morphological changes of the spermatozoa in the different region of the epididymis of the bull. Therefore the objective of the study is to assess.

1. Morphometric changes and the microscopic structural changes of the epididymis 
Piratheepan S \& Munasinghe., Sch J Agric Vet Sci, Feb, 2021; 8(2): 10-14

2. Morphological changes of the spermatozoa at different regions of the epididymis.

\section{MATERIALS AND METHOD \\ Sample collection}

Ten testes were collected from mature, healthy, indigenous bulls slaughtered at Kandy abattoir and brought to the laboratory on ice. Then the epididymis was carefully dissected from the testis. Five epididymides were used to obtain epididymal fluid to study the morphological changes of the spermatozoa during the epididymal transit while the rest was used to study the morphometry of the epididymis and microscopic structure of the epididymal epithelium.

\section{Processing of the epididymal fluid and procedure for sperm counts}

The epididymal fluid was obtained from two sites each from head, body and tail as shown in the figure 1 and the sites were named as head proximal, head distal, body proximal, body distal, tail proximal and tail distal.

The Eosin Nigrosin stain was used to study the morphological changes and abnormalities of the spermatozoa during epididymal transit. A drop of eosin and nigrosin mixture (1:4) was placed on the epididymal fluid droplet, and mixed using the edge of another slide and spread over the slide to prepare a thin smear. It was dried on a warm stage at $37^{\circ} \mathrm{C}$. Thus prepared smear were observed under oil immersion ( $\times 100)$ objective of a light microscope to assess the morphological changes of spermatozoa during the epididymal transit.

\section{Preparation of histological Section}

Epididymis was dissected out from the testis and divided into six areas namely head proximal, head distal, body proximal, body distal, tail proximal and tail distal.
Five to eight millimeter thick sections from each area of the epididymis were obtained, and fixed in formal saline for 24 hours. These were subjected to processing by using an auto tissue processor.

\section{Staining procedure \\ Haematoxylin and eosin stain \\ Routine staining procedure was followed}

\section{Van Gieson Staining Technique}

Two slides from each of the six areas of each animal were stained with Van Gieson technique to identify the presence of smooth muscle and collagen fibres around the epididymal duct.

Measurement of the volume density of tubules, interstitium, epithelium and lumen of tubules

The haematoxylin and eosin stained slides were used to measure, the volume densities of the tubules, interstitium, epithelium and the lumen of the tubules at different regions of the epididymis.

\section{Measurement of the diameter of tubules, lumen, height of the epithelium and length of stereocilia \\ A graticule with 100 units was inserted into an eye piece of a microscope and unit value of the graticule was determined against a $\times 10$ objective lens using the $100 \mathrm{~mm}$ scale slide. The height of epithelium was calculated by measuring the distance from the basement of the epithelium to the beginning of stereocilia. The length of stereocilia was calculated by measuring the length between the bases of the stereocilia to the free end of the stereocilia. All these measurements were done in millimeter $(\mathrm{mm})$ and the result were presented as mean values for each component.}

\section{STATISTICAL ANALYSIS}

Results were expressed as means or mean percentage with standard deviation. The comparison of means were done using SAS statistical package where appropriate.

\section{RESULTS}

Table-1: The spermatozoa with proximal, middle and distal cytoplasmic droplet $(\mathbf{n}=5)$

\begin{tabular}{|l|l|l|l|}
\hline $\begin{array}{l}\text { Region of the } \\
\text { epididymis }\end{array}$ & $\begin{array}{l}\text { Proximal cytoplasmic droplet } \\
(\boldsymbol{\%})\end{array}$ & $\begin{array}{l}\text { Middle cytoplasmic droplet } \\
(\boldsymbol{\%})\end{array}$ & $\begin{array}{l}\text { Distal cytoplasmic } \\
\text { droplet }(\boldsymbol{\%})\end{array}$ \\
\hline Head proximal & $74.3 \pm 9.2^{\mathrm{a}}$ & $9 \pm 2.3^{\mathrm{b}}$ & $1.3 \pm 0.6^{\mathrm{d}}$ \\
\hline Head distal & $70.2 \pm 9.4^{\mathrm{a}}$ & $5.1 \pm 1.5^{\mathrm{b}}$ & $0.8 \pm 0.3^{\mathrm{d}}$ \\
\hline Body proximal & $19.3 \pm 9.3^{\mathrm{b}}$ & $15.3 \pm 2.9^{\mathrm{a}}$ & $5 \pm 2.1^{\mathrm{d}}$ \\
\hline Body distal & $8.5 \pm 7.1^{\mathrm{c}}$ & $12.1 \pm 5.6^{\mathrm{a}}$ & $17.3 \pm 11.3^{\mathrm{c}}$ \\
\hline Tail proximal & $1.8 \pm 2.3^{\mathrm{d}}$ & $1.3 \pm 1.5^{\mathrm{b}}$ & $41.3 \pm 3.7^{\mathrm{b}}$ \\
\hline Tail distal & $2.4 \pm 2.1^{\mathrm{d}}$ & $0.9 \pm 0.7^{\mathrm{b}}$ & $39.4 \pm 11.7^{\mathrm{a}}$ \\
\hline
\end{tabular}

Mean \pm SD with different superscripts a, b, c, d, e or $\mathrm{f}$ in the same column differ significantly $(\mathrm{p}<0.05)$ 
The spermatozoa with proximal cytoplasmic droplet were found more in the head region compared to the other regions. Further a gradual decline of the number of spermatozoa with proximal cytoplasmic droplet was also observed from head to tail. The opposite was observed for the number of sperms without cytoplasmic droplets. The tail region had the lowest number of spermatozoa with proximal cytoplasmic droplet.

The spermatozoa with middle cytoplasmic droplet were higher in the body region than in head and tail regions. However, the lowest numbers of spermatozoa with middle cytoplasmic droplet were found in the tail region. The spermatozoa with distal cytoplasmic droplet were observed more in the tail region. The head had the lowest number of spermatozoa with distal cytoplasmic droplet followed by the body region.

Table-2: Abnormal spermatozoa in different regions of the cattle epididymis

\begin{tabular}{|l|l|}
\hline Area & Average of abnormalities (\%) \\
\hline Head & $10 \pm 3.5$ \\
\hline Body & $8 \pm 2.1$ \\
\hline Tail & $4.5 \pm 1.3$ \\
\hline
\end{tabular}

The abnormalities of spermatozoa were assessed using Eosin Nigrosin stained smears.

\section{Microscopic anatomy of epididymal duct}

Regional variation in the structure of the epididymis has been described in different animals. The epididymal duct was lined by a pseudostratified columnar epithelium with stereociliated cells. Principal cells (Fig 1) were the commonest cells found throughout the epididymal duct. These cells had elongated nuclei. The height of the principal cell reduced from the head region to the tail. The length of the stereocilia also reduced. The thickness of the collage layers encircling the epididymal duct was observed throughout the epididymis.

Additionally halo cells, apical cells, and basal cells (Fig 1) were present. The halocells (Fig 3) nucleus stained darkly and the cytoplasm was unstained or pale staining. Halo cells were observed throughout the epididymal duct.

Apical cells were located close to the luminal border of the epithelium. The nuclei of the apical cells located in the middle of the apical region of the cell. The basal cells were located along the basal border immediately interior to the basal lamina. The shortest stereocilia was found in the tail region.

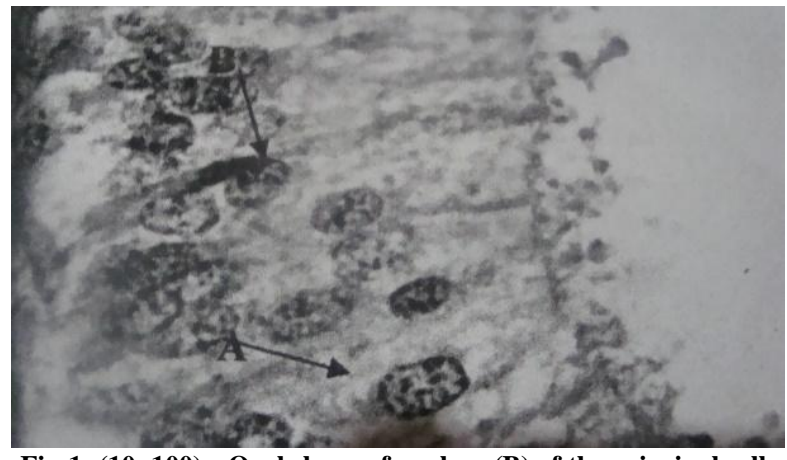

Fig-1: $(10 \times 100)$ :- Oval shape of nucleus $(B)$ of the principal cells (B)

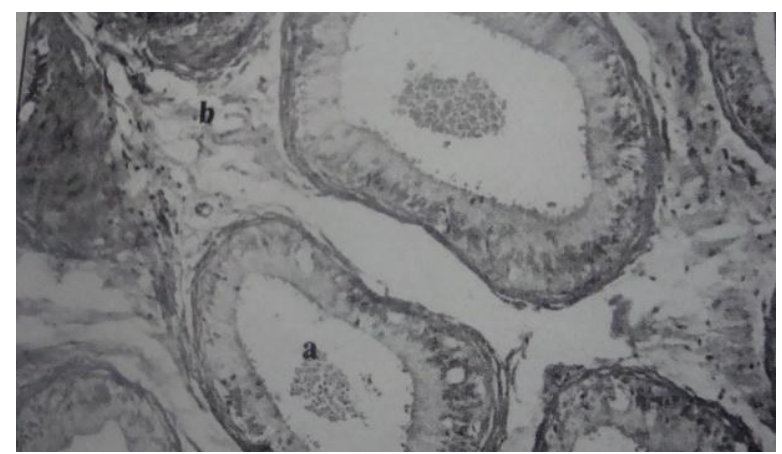

Fig-2: $(10 \times 10)$ body region loosely packed with tubules with more intestitium stained by $\mathrm{H} \& \mathrm{E}$

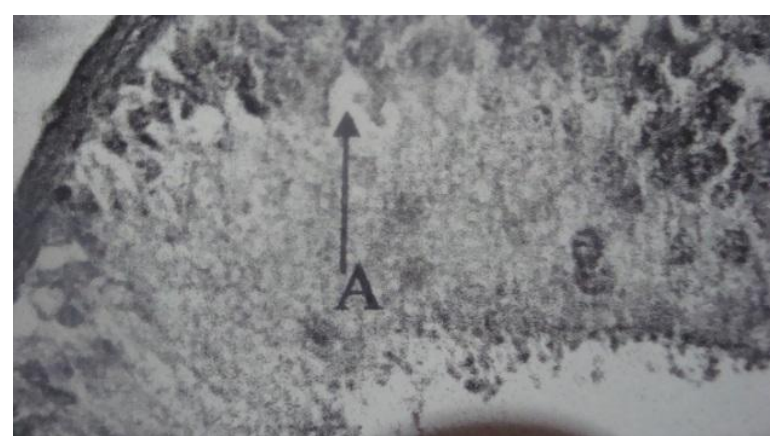

Fig-3: (10×40) epididymal duct epithelium A- Halo cells

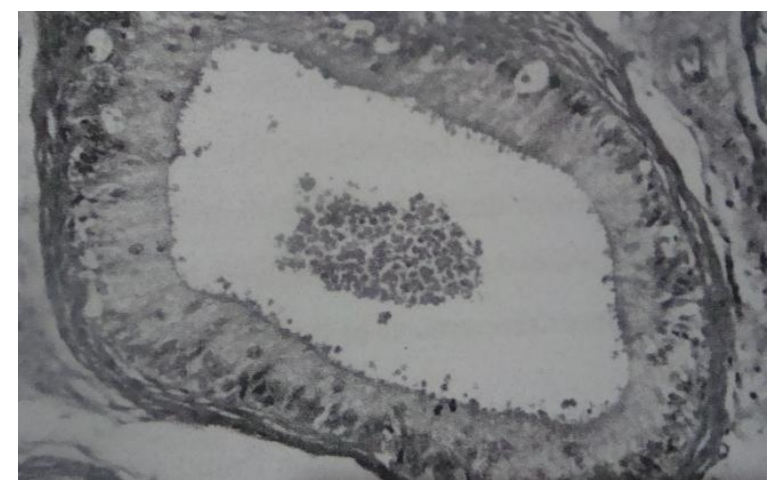

Fig-4: Amount of spermatozoa present in the body region and the height of the epithelium 
Piratheepan S \& Munasinghe., Sch J Agric Vet Sci, Feb, 2021; 8(2): 10-14

Table-3: Comparison of volume densities of tubules, interstitum, epithelium and tubular lumen in different regions of the cattle epididymis $(n=5)$

\begin{tabular}{|l|l|l|l|l|}
\hline $\begin{array}{l}\text { Region of the } \\
\text { epididymis }\end{array}$ & $\begin{array}{l}\text { Tubular volume } \\
\text { density }(\boldsymbol{\%})\end{array}$ & $\begin{array}{l}\text { Epithelial } \\
\text { volume density } \\
(\boldsymbol{\%})\end{array}$ & $\begin{array}{l}\text { Lumen volume } \\
\text { density }(\boldsymbol{\%})\end{array}$ & $\begin{array}{l}\text { Interstitial } \\
\text { volume density } \\
(\boldsymbol{\%})\end{array}$ \\
\hline Head proximal & $74.4 \pm 1.0^{\mathrm{a}}$ & $49.3 \pm 1.7^{\mathrm{a}}$ & $25.1 \pm 1.3^{\mathrm{a}}$ & $26 \pm 1.3^{\mathrm{b}}$ \\
\hline Head distal & $74.86 \pm 1.7^{\mathrm{a}}$ & $37.4 \pm 1.9^{\mathrm{b}}$ & $37.4 \pm 1.1^{\mathrm{b}}$ & $25.1 \pm 1.7^{\mathrm{b}}$ \\
\hline Body proximal & $71.8 \pm 0.3^{\mathrm{b}}$ & $38.64 \pm 1.6^{\mathrm{b}}$ & $33 \pm 0.8^{\mathrm{b}}$ & $28.2 \pm 0.6^{\mathrm{b}}$ \\
\hline Body distal & $59.5 \pm 2.0^{\mathrm{c}}$ & $24.2 \pm 1.7^{\mathrm{c}}$ & $35.2 \pm 2.3^{\mathrm{b}}$ & $40.5 \pm 2.0^{\mathrm{a}}$ \\
\hline Tail proximal & $81.42 \pm 0.9^{\mathrm{a}}$ & $26.6 \pm 1.7^{\mathrm{c}}$ & $53 \pm 2.5^{\mathrm{c}}$ & $18.5 \pm 1.3^{\mathrm{c}}$ \\
\hline Tail distal & $74.34 \pm 1.6^{\mathrm{a}}$ & $22.8 \pm 1.6^{\mathrm{d}}$ & $51.5 \pm 1.1^{\mathrm{c}}$ & $25.8 \pm 1.6^{\mathrm{b}}$ \\
\hline
\end{tabular}

Mean \pm SD with different superscripts $a, b, c, d$, e or $f$ in the same column differ significantly $(\mathrm{p}<0.05)$

The tubular volume density of different regions of the epididymis was measured to assess the compactness of the epididymal tubule in different region of the epididymis. The head and tail regions had a similar tubular volume density and found to be significantly higher than that of the body region. The interstitial tissue volume density was found to be the highest at distal part of the body compared with those of other areas. The body distal region had the lowest tubular volume and the highest interstitial volume indicating the lowest compactness of the epididymal tubules at this region.

The epithelial volume density showed a decrease from head to tail. The volume density of the tubular lumen showed an increase from head to tail.

Table-4: Comparison of diameters of tubules, lumen and the heights of epithelium and length of stereocilia of the six regions identified

\begin{tabular}{|l|l|l|l|l|}
\hline Region & $\begin{array}{l}\text { Diameter of } \\
\text { tubules }(\mathbf{m m})\end{array}$ & $\begin{array}{l}\text { Diameter of the } \\
\text { lumen }(\mathbf{m m}\end{array}$ & $\begin{array}{l}\text { Height of } \\
\text { epithelium }(\mathbf{m m})\end{array}$ & $\begin{array}{l}\text { Length } \\
\text { stereocilia }(\mathbf{m m})\end{array}$ \\
\hline Head proximal & $0.41 \pm 0.02^{\mathrm{b}}$ & $0.24 \pm 0.03^{\mathrm{b}}$ & $0.06 \pm 0.03^{\mathrm{a}}$ & $0.03 \pm 0.002^{\mathrm{a}}$ \\
\hline Head distal & $0.38 \pm 0.02^{\mathrm{b}}$ & $0.25 \pm 0.02^{\mathrm{b}}$ & $0.05 \pm 0.003^{\mathrm{a}}$ & $0.01 \pm 0.0002^{\mathrm{b}}$ \\
\hline Body proximal & $0.35 \pm 0.02^{\mathrm{b}}$ & $0.21 \pm 0.02^{\mathrm{b}}$ & $0.05 \pm 0.003^{\mathrm{a}}$ & $0.02 \pm 0.01^{\mathrm{a}}$ \\
\hline Body distal & $0.36 \pm 0.02^{\mathrm{b}}$ & $0.22 \pm 0.02^{\mathrm{b}}$ & $0.04 \pm 0.002^{\mathrm{b}}$ & $0.03 \pm 0.02^{\mathrm{a}}$ \\
\hline Tail proximal & $0.54 \pm 0.02^{\mathrm{a}}$ & $0.38 \pm 0.01^{\mathrm{a}}$ & $0.03 \pm 0.02^{\mathrm{c}}$ & $0.02 \pm 0.0001^{\mathrm{a}}$ \\
\hline Tail distal & $0.40 \pm 0.01^{\mathrm{b}}$ & $0.30 \pm 0.01^{\mathrm{a}}$ & $0.03 \pm 0.003^{\mathrm{c}}$ & $0.01 \pm 0.001^{\mathrm{b}}$ \\
\hline
\end{tabular}

Mean \pm SD with different letters $a, b, c, d$, e or $f$ in the same column differs significantly $(\mathrm{p}<0.05)$.

The diameter of the epididymal tubules was more or less similar than in all regions except proximal tail region which had the highest diameter.

The lumen diameters of the epididymal tubules were increased from head region to tail region. The luminal diameter of the epididymal duct did not show a significant difference in the head and body region but luminal diameter of the tail region was found to be significantly highest than those of the rest.

The height of epithelium showed a decrease from head to tail region. The length of stereocilia did not show a significant change except in head distal and tail distal areas where the ciliary height was found significantly lower than those of the other.

\section{DISCUSSION}

The sperms are considered immature when the cytoplasmic droplet is situated at the mid piece, but considered matured when the droplets migrate to the tail or when it get lost [5].

In this study more than $70 \%$ obtained from the caput epididymis had proximal cytoplasmic droplets indicating immaturity. However in the tail region less than $2.5 \%$ have proximal cytoplasmic droplets. This indicates that spermatozoa have become mature during epididymal transit.

Present was observed during the transit of sperm through the epididymal duct (table 2). The reduction of sperm abnormalities may be due to the removal of abnormal sperms during epididymal transit [3] and the macrophages present in the epididymis of the cattle [6] may play a role in the removal of abnormal spermatozoa.

The epididymal duct is lined by pseudostratified columnar epithelium and surrounded by few layers of collagen and smooth muscle. Regional variation of the pseudostratified columnar epithelium of the epididymal duct was assessed in this study. The height of the epithelium reduced progressively towards the tail region. The length of stereocilia was less in the tail region and the body region possessed the longest stereocilia. This may be due to the coiling nature of the epididymal duct. It is possible to get the tubules belongs to head region in the body of the epididymis. 
Piratheepan S \& Munasinghe., Sch J Agric Vet Sci, Feb, 2021; 8(2): 10-14

The epididymal duct composed of four types of cells, basal cells, apical cells and halo cells. The most common cell types found in all the regions of epididymis were principal cells with elongated nucleus. Apical cells are not reported to be present in the epididymal duct of all mammals but Goyal [6] reported that they were present in goat. The apical cells are characterized by the apical location of the nucleus. Basal cells became more frequent in the body region an observation also reported by Vidyadaran et al. [7]. The basal cells are situated in the base of the tubules.

A higher tubular volume density was observed in the head and tail regions of the epididymis when compared with that of the body and the reverse was observed for the interstitial volume density in these regions indicating the compact arrangement of the epididymal tubule in the head to tail regions. Though the reason for this arrangement is not known, similar observation is made by Nicander and Glover [8] in hamster epididymis.

In the tail region, the volume density of the epithelium is low and luminal volume density of the tubule was high. The height of the epithelium was found to be more columnar in the head region [7].

The tubular diameter did not show a significant variation in different regions except in the proximal tail. However luminal diameter of the tubules showed a significant increase in the tail region compared with those of other regions.

In this study the head regions was with greater volume density of tubules and this may be due to the narrower lumen and taller epithelium with longer stereocilia present in head region of the epididymis also reported by Nicander and Glover [9]. The body had loosely packed tubules which had narrow lumen.

As the tubular diameter is not changed very much during the cause of epididymal tube, the increase of the luminal diameter of the tail compared with that of the head and body is mainly due to the decrease of the height of the epididymal epithelium and stereocilia. The tail region had wider lumen, shorter epithelium with shorter stereocilia than in the other regions. All these contribute to increasing the volume of the lumen in the tail region for the storage of sperms. The head region the tubule volume was high but the lumen volume was low.

The height of epithelium was found to be more columnar in the head region was observed in this study and it is also reported by Vidyadaran et al., [7]. The highest height of the epithelium and the stereocilia were observed in the head region which is similar to the observation made by Nicander and Glover 1972.
In the present study immersion fixation of the tissue was done due to convenience but if the perfusion method was utilized the distortion of tissue and the stereocilia can be reduced to minimum.

\section{CONCLUSION}

It is established that sperm maturation occur during epididymal transit and that the cytoplasmic droplet migrates from a proximal position to a distal position during maturation. The present study clearly showed that cytoplasmic droplet had translocated to a position in the tail of the sperm obtained from the cauda epididymis. The total number of abnormalities of spermatozoa decreased from head to tail region of epididymis. From the histological studies it was confirmed that four types of cells were present in the epididymal duct in cattle, and has been reported for several other mammals. From the volume density studies it may be concluded that the storage areas for sperms in the cauda epididymis is increased due to an increase in the luminal diameter caused by a decreased in epithelial height and length of stereocilia.

\section{REFERENCE}

1. Hafez ES, Hafez B. Reproduction in farm animals. (C) Lippincott williams \& wilkins. Maryland. USA. 2000.

2. Dyce KM, Sack WO, Wensing CJ. Textbook of veterinary anatomy-E-Book. Elsevier Health Sciences; 2009 Dec 3.

3. Gunawardana VK, Ariyaratna HB, Navaratne MA. The Epididymis of the Prepubertal Swamp Buffalo (Bubalus bubalis): Histological Studies. Buffalo Journal. 1995;11:273-82.

4. Rao PS, Jessup RE, Rolston DE, Davidson JM, Kilcrease DP. Experimental and mathematical description of nonadsorbed solute transfer by diffusion in spherical aggregates. Soil Science Society of America Journal. 1980 Jul;44(4):684-8.

5. Cooper A. The inmates are running the asylum: Why high-tech products drive us crazy and how to restore the sanity. Indianapolis: Sams; 2004 Feb 1.

6. Goyal HO. Morphology of the bovine epididymis. American Journal of Anatomy. 1985 Feb;172(2):155-72.

7. Harisah M, Azmi TI, Hilmi M, Vidyadaran MK, Bongso TA, Nava ZM, Momongan V, Basrur PK. Identification of crossbred buffalo genotypes and their chromosome segregation patterns. Genome. 1989 Dec 1;32(6):999-1002.

8. Nicander L, Malmqvist M. Ultrastructural observations suggesting merocrine secretion in the initial segment of the mammalian epididymis. Cell and Tissue Research. 1977 Nov 1;184(4):487-90.

9. Glover TD, Nicander L. Some aspects of structure and function in the mammalian epididymis. Journal of reproduction and fertility. Supplement. 1971 May;13:Suppl-13. 